\title{
Post-TTM Rebound Pyrexia after Ischemia-Reperfusion Injury Results in Sterile Inflammation and Apoptosis in Cardiomyocytes
}

\author{
Giang Tong $\triangle{ }^{1}$ Nalina N. A. von Garlen, ${ }^{1}$ Sylvia J. Wowro, ${ }^{1}$ Phuong D. Lam, ${ }^{1}$ Jana Krech, ${ }^{1}$ \\ Felix Berger, ${ }^{1,2}$ and Katharina R. L. Schmitt ${ }^{1}$ \\ ${ }^{1}$ Department of Congenital Heart Disease/Pediatric Cardiology, Universitäres Herzzentrum Berlin-Medical Heart Center of Charité \\ and German Heart Institute Berlin, Augustenburger Platz 1, 13353 Berlin, Germany \\ ${ }^{2}$ Department of Pediatric Cardiology, Charité-Universitätsmedizin Berlin, Corporate Member of Freie Universität Berlin, \\ Humboldt-Universität zu Berlin and Berlin Institute of Health, Berlin, Germany
}

Correspondence should be addressed to Giang Tong; giang.tong@charite.de

Received 16 August 2019; Accepted 4 November 2019; Published 21 November 2019

Guest Editor: Alessio Rungatscher

Copyright ( 2019 Giang Tong et al. This is an open access article distributed under the Creative Commons Attribution License, which permits unrestricted use, distribution, and reproduction in any medium, provided the original work is properly cited.

Introduction. Fever is frequently observed after acute ischemic events and is associated with poor outcome and higher mortality. Targeted temperature management (TTM) is recommended for neuroprotection in comatose cardiac arrest survivors, but pyrexia after rewarming is proven to be detrimental in clinical trials. However, the cellular mechanisms and kinetics of postTTM rebound pyrexia remain to be elucidated. Therefore, we investigated the effects of cooling and post-TTM pyrexia on the inflammatory response and apoptosis in a cardiomyocyte ischemia-reperfusion (IR) injury model. Methods. HL-1 cardiomyocytes were divided into the following groups to investigate the effect of oxygen-glucose deprivation/reperfusion $(\mathrm{OGD} / \mathrm{R})$, hypothermia $\left(33.5^{\circ} \mathrm{C}\right)$, and pyrexia $\left(40^{\circ} \mathrm{C}\right)$ : normoxia controls maintained at $37^{\circ} \mathrm{C}$ and warmed to $40^{\circ} \mathrm{C}$, OGD/R groups maintained at $37^{\circ} \mathrm{C}$ and cooled to $33.5^{\circ} \mathrm{C}$ for $24 \mathrm{~h}$ with rewarming to $37^{\circ} \mathrm{C}$, and $\mathrm{OGD} / \mathrm{R}$ pyrexia groups further warmed from 37 to $40^{\circ} \mathrm{C}$. Caspase- 3 and RBM3 were assessed by Western blot and TNF- $\alpha$, IL-6, IL-1 $\beta$, SOCS3, iNOS, and RBM3 transcriptions by RT-qPCR. Results. OGD-induced oxidative stress (iNOS) in cardiomyocytes was attenuated post-TTM by cooling. Cytokine transcriptions were suppressed by OGD, while reperfusion induced significant TNF- $\alpha$ transcription that was exacerbated by cooling. Significant inductions of TNF- $\alpha$, IL-6, IL-1 $\beta$, and SOCS3 were observed in noncooled, but not in cooled and rewarmed, OGD/R-injured cardiomyocytes. Further warming to pyrexia induced a sterile inflammatory response in OGD/R-injured groups that was attenuated by previous cooling, but no inflammation was observed in pyrexic normoxia groups. Moreover, cytoprotective RBM3 expression was induced by cooling but suppressed by pyrexia, correlating with apoptotic caspase-3 activation. Conclusion. Our findings show that maintaining a period of post-TTM "therapeutic normothermia" is effective in preventing secondary apoptosis-driven myocardial cell death, thus minimizing the infarct area and further release of mediators of the innate sterile inflammatory response after acute IR injury.

\section{Introduction}

Therapeutic hypothermia (TH) is the standard of care for neuroprotection in selected term newborns with hypoxicischemic encephalopathy (HIE) and is most effective when applied at $33.5^{\circ} \mathrm{C}$ for 72 hours [1]. Currently, a targeted temperature management (TTM) of $32-36^{\circ} \mathrm{C}$ for $24-48$ hours is the recommended guideline for mitigating neurological injury in comatose adults with out-of-hospital cardiac arrest $[2,3]$. However, the development of fever after rewarming from TTM, termed rebound pyrexia, has been observed in $41 \%$ of surviving patients in a multicenter cohort study [4]. They defined pyrexia as a temperature $\geq 38^{\circ} \mathrm{C}$ within $24 \mathrm{~h}$ following rewarming from postarrest TTM, and pyrexia temperature $>38.7^{\circ} \mathrm{C}$ was associated with worse neurological outcome but not overall lower survival at discharge. Recent randomized TTM control trials even suggest that the prevention of fever or temperature variability by actively maintaining the patient's temperature at $36^{\circ} \mathrm{C}$ may be just as effective for long-term neurological outcomes as applying mild $\mathrm{TH}$ to 
approximately $33^{\circ} \mathrm{C}[5,6]$. Moreover, Rungatscher et al. observed that postoperative hyperthermia $\left(>37^{\circ} \mathrm{C}\right)$ after rewarming from deep hypothermic circulatory arrest was associated with increased morbidity and mortality [7]. While the adverse effects of experimentally induced fever on neuronal damage after global ischemia have been observed [8], the effects of post-TTM rebound pyrexia on ischemia-reperfusion- (IR-) injured cardiomyocytes remain to be elucidated.

Acute myocardial infarction (AMI) has been shown to result in increased expression of proinflammatory cytokines, including tumor necrosis factor- (TNF-) $\alpha$, interleukin- (IL-) 6 , and IL-1 $\beta$ [9], that can lead to cardiac cell death and dysfunction, as well as ventricular remodeling [10]. Moreover, elevated blood concentrations of IL- 6 and TNF- $\alpha$ have been reported as independent predictors of mortality in this cohort $[11,12]$. Although the majority of proinflammatory cytokines and chemokines are derived from infiltrating monocytes/macrophages to the infarct site after AMI, they are also expressed and secreted by resident cardiac cells [13]. Cardiomyocytes make up $25 \%$ of cells in the normal heart and play an active role in mediating innate inflammatory responses, which can result in acute inflammation after IR injury [14]. Therefore, controlling cytokine release from resident cardiomyocytes is a plausible strategy for preventing further tissue damage following prolonged ischemia-reperfusion injury.

We previously demonstrated that IR injury simulated by exposure to oxygen-glucose deprivation (OGD) and subsequent reperfusion $(\mathrm{OGD} / \mathrm{R})$ resulted in reduced ATP production, leading to myocardial cell death [15]. Moreover, intra-OGD therapeutic hypothermia (IOTH) attenuated mitochondrial impairment, restored cellular metabolic activity, attenuated cardiomyocyte cell death, and induced RNA binding motif protein 3 (RBM3) expression, a cold shock protein with cytoprotective properties that is expressed in response to hypothermia and various other mild stresses $[15,16]$. However, the effect of hypothermia and subsequent rewarming to normothermia or pyrexia on the sterile inflammatory response in an OGD/R cardiomyocyte injury model remains to be elucidated. Therefore, we investigated the efficacy of moderate therapeutic hypothermia $\left(33.5^{\circ} \mathrm{C}\right)$ to attenuate the ischemia/reperfusion injury-mediated sterile inflammatory response and the adverse effects of rebound pyrexia in a murine cardiomyocyte model. Additionally, we also investigated the effect of rebound pyrexia on RBM3 expression and further myocardial cell death after an acute ischemia-reperfusion injury.

\section{Materials and Methods}

2.1. HL-1 Cell Culture. HL-1 cardiomyocytes are derived from the murine atrial AT-1 tumor cell lineage and were obtained from William C. Claycomb, Ph.D. (LSU Health Sciences Center, New Orleans, LA, USA). They are reported to show spontaneous contractions and a phenotype comparable to adult cardiomyocytes [17] and were cultured following the methods of Krech et al. [16]. Briefly, culture flasks and Petri dishes were precoated with $0.2 \mu \mathrm{g} / \mathrm{cm}^{2}$ fibronectin in $0.02 \%$ gelatine for $1 \mathrm{~h}$ at $37^{\circ} \mathrm{C}$. Cardiomyocytes were cultured at
$21 \% \mathrm{O}_{2}$ and $5 \% \mathrm{CO}_{2}$ in Claycomb Medium (Sigma-Aldrich), supplemented with 10\% FBS (Sigma-Aldrich), $50 \mu \mathrm{g} / \mathrm{ml}$ Primocin (InvivoGen), $2 \mathrm{mM}$ L-glutamine (Merck Millipore), and $0.1 \mathrm{mM}$ norepinephrine (Sigma-Aldrich). Cells were passaged upon reaching $90 \%$ confluency at $1: 2$ to $1: 5$ using trypsin/EDTA (0.05/0.02\%, respectively; Biochrom). HL-1 cardiomyocytes were divided into the following groups to investigate the effect of $\mathrm{OGD} / \mathrm{R}$, hypothermia $\left(33.5^{\circ} \mathrm{C}\right)$, and pyrexia $\left(40^{\circ} \mathrm{C}\right)$ : normoxia control groups maintained at $37^{\circ} \mathrm{C}$ and warmed to $40^{\circ} \mathrm{C}, \mathrm{OGD} / \mathrm{R}$ groups maintained at $37^{\circ} \mathrm{C}$ and cooled to $33.5^{\circ} \mathrm{C}$ for 24 hours with subsequent rewarming to $37^{\circ} \mathrm{C}$, and $\mathrm{OGD} / \mathrm{R}$ pyrexia groups further warmed from 37 to $40^{\circ} \mathrm{C}$.

\subsection{Oxygen-Glucose Deprivation/Reperfusion (OGD/R).} Ischemia-reperfusion injury was simulated in vitro by exposure to $\mathrm{OGD} / \mathrm{R}$, as previously established in our laboratory [16]. Briefly, HL-1 cardiomyocytes were deprived of oxygen and glucose for 6 hours in glucose/serum-free DMEM (Biochrom) at $0.2 \% \mathrm{O}_{2}$ and $5 \% \mathrm{CO}_{2}$ in a $\mathrm{CO}_{2}$ incubator (Binder) [15]. Control groups were kept at normoxia $(21 \%$ $\mathrm{O}_{2}$ ) in DMEM containing glucose (Biochrom) and $10 \%$ FBS (Biochrom). After $6 \mathrm{~h}$ of OGD, reperfusion was simulated by restoration of nutrients in complete Claycomb Medium (Sigma-Aldrich) and $21 \% \mathrm{O}_{2}$ in all the groups. All experimental media were supplemented with $50 \mu \mathrm{g} / \mathrm{ml}$ Primocin (InvivoGen) and $2 \mathrm{mM}$ L-glutamine (Merck Millipore).

2.3. Targeted Temperature Management (TTM). We previously established a time-temperature protocol for intraischemic cooling $\left(33.5^{\circ} \mathrm{C}\right)$ for the HL-1 cardiomyocytes, based on the guidelines from the European Resuscitation Council for cardiac arrest survivors (see Figure 1) $[15,18]$. Briefly, normothermic OGD/R-injured groups were maintained at $37^{\circ} \mathrm{C}$ for the duration of the experiment, while TTM groups were cooled to $33.5^{\circ} \mathrm{C}$ after 3-hour exposure to OGD and maintained during simulated reperfusion for 24 hours. All experimental cooled groups were then rewarmed to and maintained at $37^{\circ} \mathrm{C}$. Cooled pyrexia groups were maintained at $37^{\circ} \mathrm{C}$ for only 2 hours, then along with normothermic pyrexia groups further warmed to $40^{\circ} \mathrm{C}$ at $29 \mathrm{~h}$ after experimental start and maintained for an additional 24 hours. Samples were analyzed directly after OGD (6 h), 2 hours into the early reperfusion phase $(8 \mathrm{~h})$, the end of the cooling phase $(27 \mathrm{~h}), 2$ hours after rewarming to normothermia $(29 \mathrm{~h})$, and 2,12 , and 24 hours after initiation of pyrexia $(31,41$, and $53 \mathrm{~h}$ after experimental start, respectively) in order to thoroughly investigate the effects of OGD/R, TTM, and pyrexia on the cardiomyocytes.

2.4. Protein Extraction and Western Blot Analysis. Caspase-3 activation and RBM3 expression were assessed by Western blot following the methods of Krech et al. [16]. Briefly, HL1 cardiomyocytes were seeded onto $22 \mathrm{~cm}^{2}$ cell culture dishes at a density of $5 \times 10^{5}$ cells per dish $48 \mathrm{~h}$ before conducting the experiments as described above. Attached cells were mechanically scratched off the plate surface and lysed using a modified RIPA buffer (50 mM Tris- $\mathrm{HCl}, \mathrm{pH} 7.5$ ), $150 \mathrm{mM}$ sodium chloride, $1 \%$ Triton $\mathrm{X}-100,0.1 \%$ sodium dodecyl 


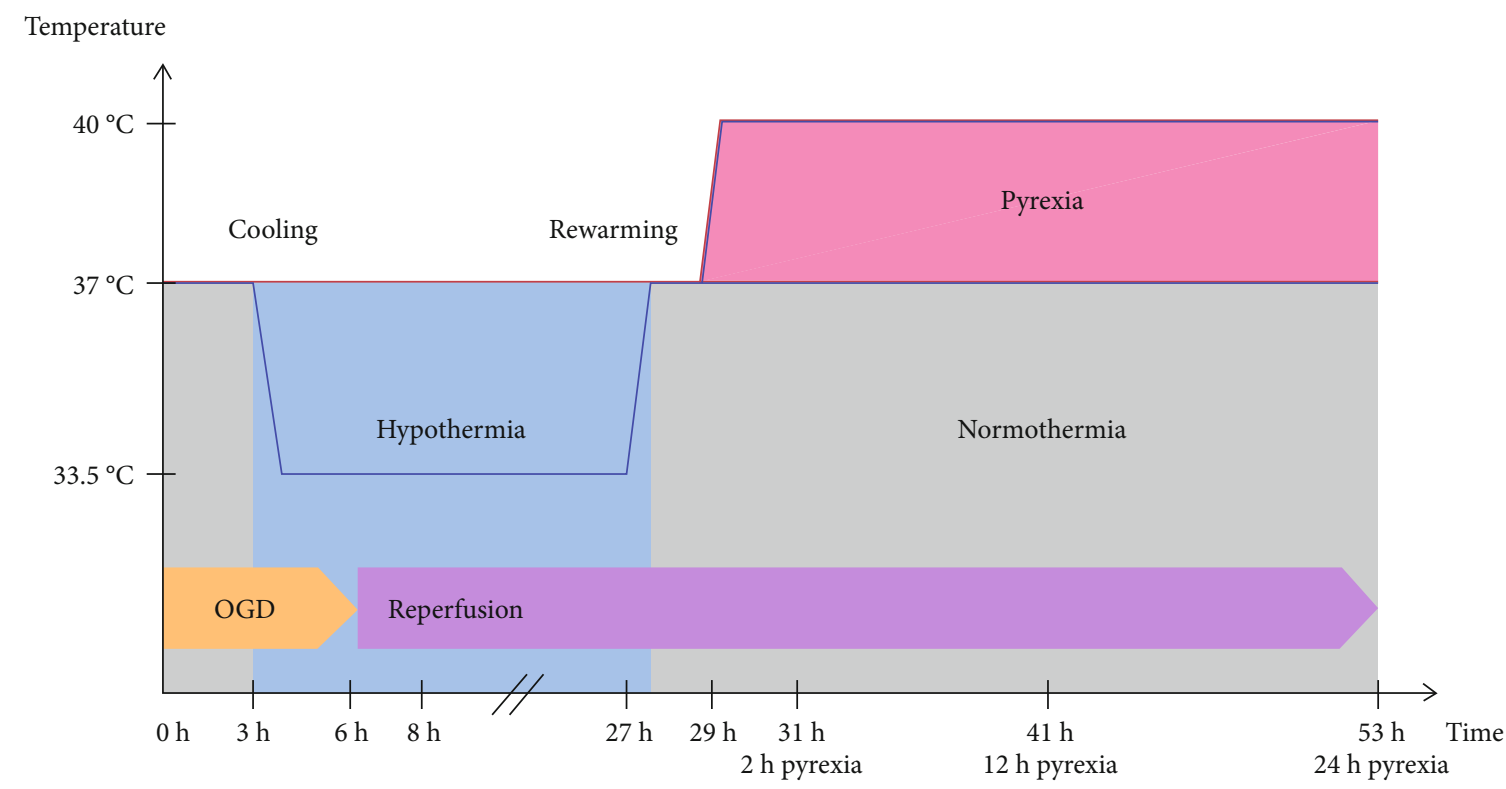

Figure 1: Experimental time-temperature protocol. Normothermic OGD/R-injured groups were maintained at $37^{\circ} \mathrm{C}$ for the duration of the experiment, while TTM groups were cooled to $33.5^{\circ} \mathrm{C}$ after 3 -hour exposure to OGD and maintained during simulated reperfusion for 24 hours. All experimental cooled groups were then rewarmed to and maintained at $37^{\circ} \mathrm{C}$. Cooled pyrexia groups were maintained at $37^{\circ} \mathrm{C}$ for only 2 hours and then along with normothermic pyrexia groups further warmed to $40^{\circ} \mathrm{C}$ at $29 \mathrm{~h}$ after experimental start and maintained for an additional 24 hours. Samples were analyzed directly after OGD (6h), 2 hours into the early reperfusion phase ( $8 \mathrm{~h}$ ), the end of the cooling phase $(27 \mathrm{~h}), 2$ hours after rewarming to normothermia $(29 \mathrm{~h})$, and then 2,12 , and 24 hours after initiation of pyrexia (31, 41, and $53 \mathrm{~h}$ after experimental start, respectively).

sulfate, $0.5 \%$ Na-deoxycholate, $2 \mathrm{mM}$ ethylenediaminetetraacetic acid, $1 \mathrm{mM}$ phenylmethylsulfonyl fluoride, sodium fluoride, and protease inhibitor cocktail 3 (all from SigmaAldrich) and quantified using a BCA-Protein Assay Kit (Pierce Biotechnology). Protein extracts $(30 \mu \mathrm{g})$ were electrophoresed on $15 \%$ SDS polyacrylamide gels and transferred to PVDF membranes. Membranes were blocked with 5\% nonfat dried milk powder in Tris-buffered saline+0.1\% Tween-20 and incubated with anti-caspase-3 (1:500) and anti-RBM3 (1:1000) or blocked with 5\% BSA for incubation with anti- $\beta$-actin $(1: 15,000)$ at $4^{\circ} \mathrm{C}$ overnight. All primary antibodies were rabbit polyclonals purchased from Cell Signaling Technology. An HRP-conjugated donkey anti-rabbit secondary antibody (Dianova) was incubated for $1 \mathrm{~h}$ and detected with SuperSignal ${ }^{\mathrm{TM}}$ West Dura Chemiluminescent Substrate (Pierce Biotechnology). Densitometry quantification of the Western blots was performed using Image Lab (Bio-Rad Laboratories) and normalized to $\beta$-actin for equal protein loading.

2.5. RNA Isolation and $R T-q P C R$. Sterile inflammatory response was assessed by real-time quantitative PCR (RTqPCR). Total RNA from HL-1 cardiomyocytes was isolated using the GeneMatrix Universal RNA Purification Kit (Roboklon) according to the manufacturer's instructions. RNA concentration and purity were determined by spectrophotometric measurements at 260 and $280 \mathrm{~nm}$ using NanoDrop 2000 (NanoDrop) and agarose gel electrophoresis. cDNA was transcribed from $1.5 \mu \mathrm{g}$ total RNA using a High-Capacity cDNA Reverse Transcription Kit (Applied Biosystems) using a PTC200 Thermal Cycler (MJ Research).
Table 1: TaqMan ${ }^{\circledR}$ Gene Expression Assays.

\begin{tabular}{lc}
\hline Gene & Assay ID \\
\hline GAPDH & 99999915_g1 \\
IL-1 $\beta$ & $00434228 \_m 1$ \\
IL-6 & $00446190 \_m 1$ \\
iNOS & $00440502 \_m 1$ \\
RBM3 & 01609819_g1 \\
SOCS3 & 00545913_s1 \\
TNF- $\alpha$ & 00443260_g1 \\
\hline
\end{tabular}

Expression of target genes and the endogenous control glyceraldehyde 3-phosphate dehydrogenase (GAPDH) was assessed by real-time $\mathrm{qPCR}$ using the TaqMan ${ }^{\circledR}$ Gene Expression Assays (see Table 1) and StepOnePlus ${ }^{\mathrm{TM}}$ RealTime PCR System (Applied Biosystems) according to the manufacturer's recommendations. Reactions with no reverse transcripts and templates were included as negative controls. Relative quantification of gene expression was normalized to the housekeeping gene GAPDH, using the $2^{-\Delta \Delta \mathrm{ct}}$ method, and illustrated as fold change [15].

2.6. Statistical Analysis. Data were analyzed and graphed using GraphPad Prism 5 (GraphPad Software). Results were expressed as means \pm standard deviations. Experiments were independently repeated at least three times. One-way ANOVA followed by Tukey's posttest was used for multiple group comparison, and $p<0.05$ was considered statistically significant. 


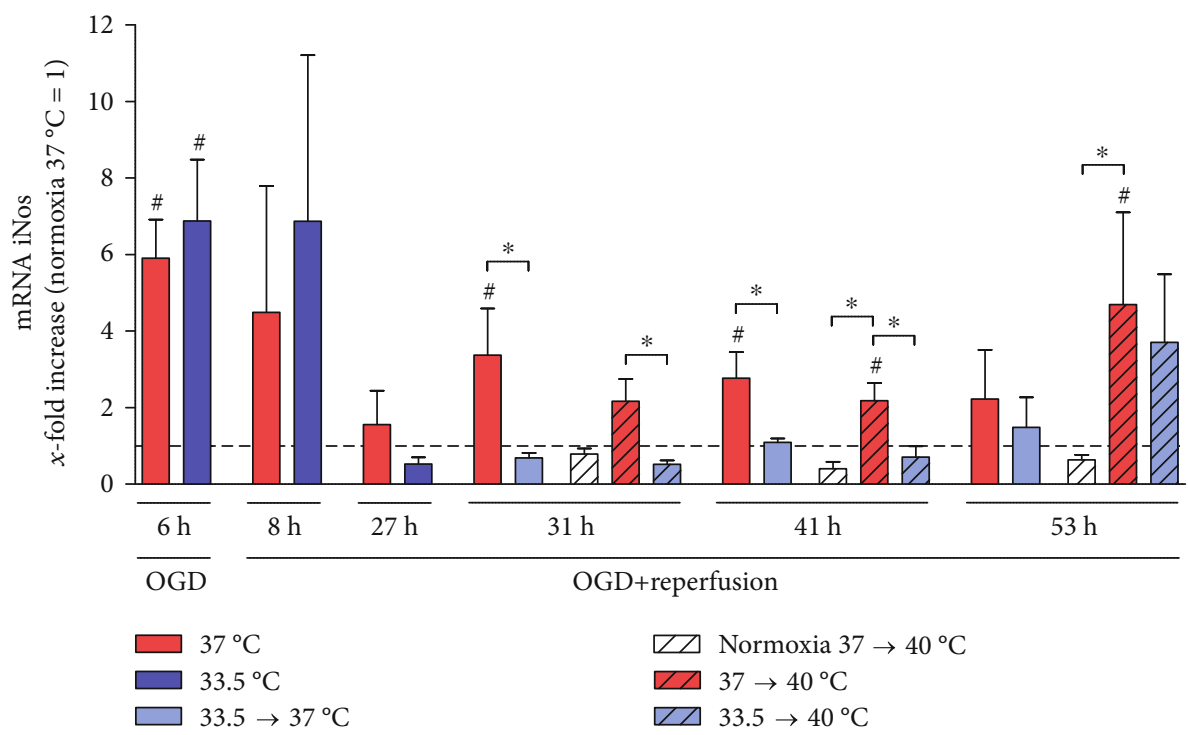

FIgURE 2: Hypothermia attenuated OGD/R- and pyrexia-induced iNOS expression in the HL-1 cardiomyocytes in the late reperfusion and pyrexia phase $\left(31-53 \mathrm{~h}\right.$ ). Data from 3 to 5 independent experiments is presented as mean \pm SD. ${ }^{*} p \leq 0.05$ and ${ }^{\#} p \leq 0.05$ as compared to normoxia control at $37^{\circ} \mathrm{C}$ (normalized to 1 ).

\section{Results}

3.1. OGD/R Induces Oxidative Stress in HL-1 Cardiomyocytes. We investigated the effect of exposure to OGD/R, hypothermia, and pyrexia on the inducible NO synthase (iNOS) expression in the HL-1 cardiomyocytes (see Figure 2) and observed a significant increase in iNOS expression relative to normoxia control after exposure to OGD that was not attenuated by the brief period of hypothermia $(6 \mathrm{~h})$, but no significant increases were observed in the reperfusion phase $(8-27 \mathrm{~h})$. Even after posthypothermia rewarming to $37^{\circ} \mathrm{C}$, iNOS transcription stayed significantly attenuated by cooling compared to noncooled OGD/R groups (29-41 h). Further warming to pyrexia also resulted in a significant increase in iNOS expression (31-53 h) that was attenuated by cooling in the early pyrexia phase (31-41 h), but not after 24 hours (53 h). Interestingly, exposure to pyrexia alone did not induce increased iNOS transcription in the undamaged control cardiomyocytes that were warmed to pyrexia.

3.2. OGD/R-Induced Sterile Inflammatory Response Is Exacerbated by Pyrexia. We investigated the effect of hypothermia and subsequent warming to pyrexia on OGD/Rinduced TNF- $\alpha$ (see Figure 3(a)), IL-6 (see Figure 3(b)), and IL- $1 \beta$ (see Figure $3(\mathrm{c})$ ) expression, as well as the negative regulator of cytokine signaling, SOCS-3 (see Figure 3(d)), in the HL- 1 cardiomyocytes. A significant decrease in TNF- $\alpha$ transcription relative to normoxia control was observed after exposure to OGD (6h) that was followed by a significant spike in the early reperfusion phase, which was augmented by cooling ( $8 \mathrm{~h})$. TNF- $\alpha$ transcription eventually diminished to normoxia control levels in the cooled groups $(27-53 \mathrm{~h})$, but stayed significantly higher in the noncooled groups at the later reperfusion time points (31-41 h). Warming OGD/R-injured cardiomyocytes to pyrexia also resulted in significantly higher TNF- $\alpha$ transcription relative to normoxia controls at $37^{\circ} \mathrm{C}$ as well as normoxia groups warmed to pyrexia (31-53 h), but not to the OGD/R-injured groups that were either maintained at or rewarmed to $37^{\circ} \mathrm{C}$ (31-41 h). Additionally, no significant attenuations by cooling were observed in the OGD/R-injured groups after 24-hour exposure to pyrexia $(53 \mathrm{~h})$.

Similar to TNF- $\alpha$, IL-6 transcription was also significantly suppressed relative to normoxia control by exposure to OGD (6h). Unlike TNF- $\alpha$, IL- 6 transcription did not peak in the reperfusion phase $(8-29 \mathrm{~h})$. A brief increase in IL-6 transcription was observed in the noncooled OGD/R group, but not in the cooled OGD/R group in the late reperfusion phase $(31 \mathrm{~h})$. Further warming to pyrexia resulted in the greatest increases in IL- 6 transcriptions in both cooled and noncooled $\mathrm{OGD} / \mathrm{R}$ groups relative to both normoxia control and $\mathrm{OGD} / \mathrm{R}$ groups maintained at or rewarmed to $37^{\circ} \mathrm{C}$ (41 and $53 \mathrm{~h}$ ). Even though previous cooling attenuated this increase in IL-6 after 12-hour exposure to pyrexia $(41 \mathrm{~h})$ in the cooled OGD/R group compared to the noncooled OGD/R group, this protective effect was no longer observed after 24-hour exposure to pyrexia ( $53 \mathrm{~h}$ ). Pyrexia alone however did not induce IL-6 expression in the undamaged normoxia control cardiomyocytes.

The expression of IL- $1 \beta$ was observed to be comparable to IL-6 expressions in all experimental groups during the $\mathrm{OGD} / \mathrm{R}$ phase and was not significantly induced by hypothermia. However, a significantly lower IL- $1 \beta$ transcription was observed in the cooled OGD/R group rewarmed to $37^{\circ} \mathrm{C}$ relative to the noncooled OGD/R-injured group $(31 \mathrm{~h})$. Moreover, warming to pyrexia resulted in a significant increase in IL- $1 \beta$ transcription in the noncooled OGD/Rinjured group ( $53 \mathrm{~h})$.

Suppressor of cytokine signaling 3 (SOCS-3) gene expression was significantly decreased by OGD $(6 \mathrm{~h})$ relative to normoxia control, recovered to normoxia level in the reperfusion phase, and was significantly induced in the noncooled 


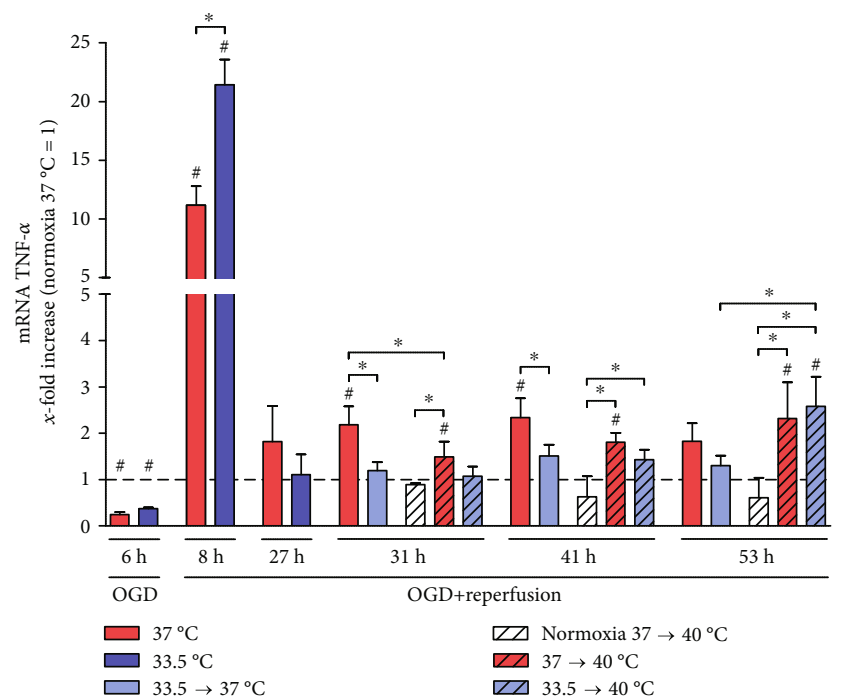

(a)

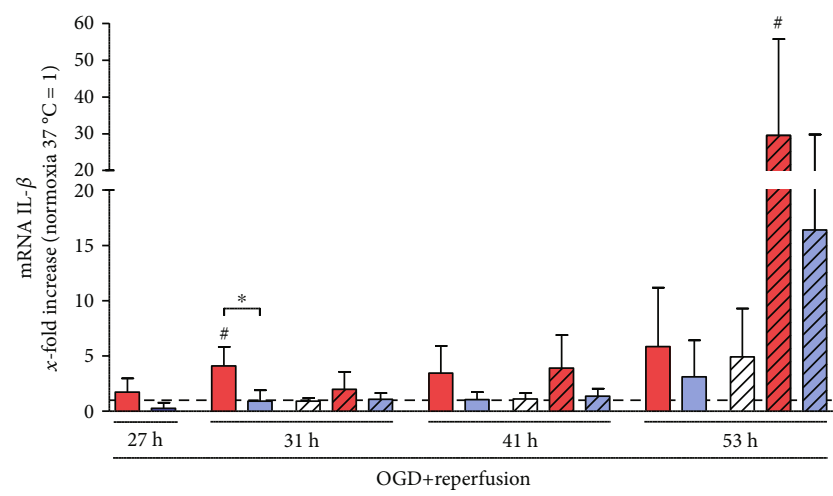

(c)

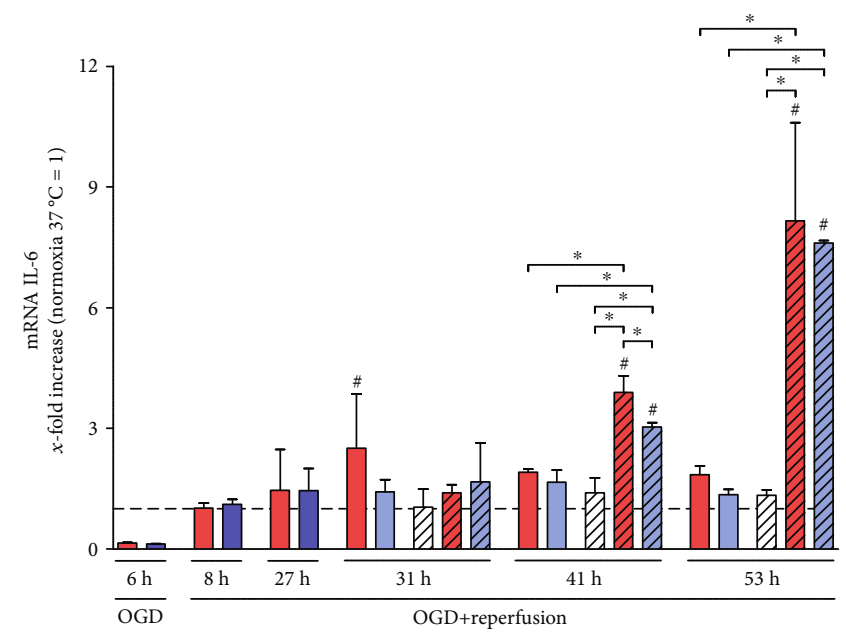

(b)

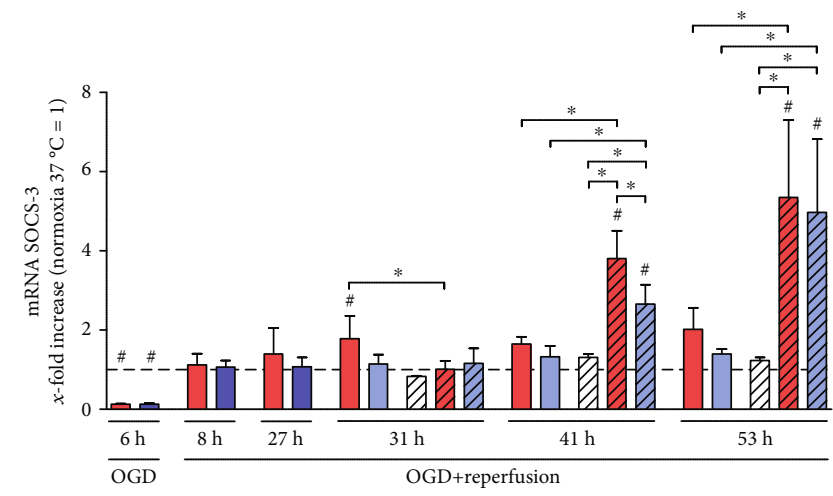

(d)

Figure 3: (a) TNF- $\alpha$ expression was suppressed by OGD (6h). OGD/R-induced damage leads to a significant increase in TNF- $\alpha$ expression relative to normoxia control in the early reperfusion phase $(8 \mathrm{~h})$, which was significantly higher in the cooled than in the noncooled group. During late reperfusion (31 and $41 \mathrm{~h}$ ), however, the noncooled OGD/R-injured group stayed significantly elevated, whereas the cooled group showed no such effect. Further warming to pyrexia induced TNF- $\alpha$ expression in OGD/R-injured groups irrespective of previous temperature management. (b) IL-6 expression was suppressed by OGD (6h), and hypothermia temporarily attenuated pyrexia-induced IL-6 expression in OGD/R-injured cardiomyocytes $(41 \mathrm{~h})$. (c) Pyrexia increased IL- $1 \beta$ expression in noncooled OGD/R-injured cardiomyocytes that was not attenuated by hypothermia $(53 \mathrm{~h})$. (d) SOCS-3 expression was significantly inhibited by OGD $(6 \mathrm{~h})$ and increased during late reperfusion $(31 \mathrm{~h})$ in the noncooled OGD/R-injured groups. Warming to pyrexia significantly induced SOCS-3 expression in both cooled and noncooled OGD/R-injured cardiomyocytes and was briefly attenuated by hypothermia $(41 \mathrm{~h})$. Data from 3 to 5 independent experiments is presented as mean $\pm \mathrm{SD} .{ }^{*} p \leq 0.05$ and ${ }^{\#} p \leq 0.05$ as compared to normoxia control at $37^{\circ} \mathrm{C}$ (normalized to 1 ).

OGD/R-injured group but not in the cooled groups (29 and $31 \mathrm{~h}$ ). Rewarming to pyrexia, however, induced significant increases in SOCS-3 transcription in the OGD/R-injured cardiomyocytes compared to both normoxia control and corresponding OGD/R-injured groups maintained at or rewarmed to $37^{\circ} \mathrm{C}$ (41 and $53 \mathrm{~h}$ ), which was briefly attenuated by previous cooling after 12 -hour exposure to pyrexia $(41 \mathrm{~h})$. Interestingly, no significant increased SOCS-3 expression was observed in the undamaged normoxia control cardiomyocytes warmed to $40^{\circ} \mathrm{C}$.

3.3. Cold Shock RBM3 Is Induced by Hypothermia and Suppressed by Pyrexia. Exposure to moderate hypothermia for 24 hours significantly induced both RBM3 mRNA and protein expressions in the HL-1 cardiomyocytes $(27 \mathrm{~h})$ (see Figure 4). Induced RBM3 expression was observable up to 14 hours after rewarming to normothermia $\left(37^{\circ} \mathrm{C}\right.$ at 29,31 , and $41 \mathrm{~h}$ ), 2 hours after further warming to pyrexia $(31 \mathrm{~h})$, and gradually returned to baseline levels after 24 hours. However, prolonged exposure to pyrexia for 24 hours resulted in a significant suppression of RBM3 expression in all groups at the mRNA and protein levels $(53 \mathrm{~h})$.

3.4. Pyrexia Induces Apoptosis in OGD/R-Injured Cardiomyocytes. Further warming to fever induced a secondary cell death mechanism in the cardiomyocytes exposed to OGD/R. We observed significant increases in caspase-3 activation, a hallmark of the apoptosis programmed cell death 


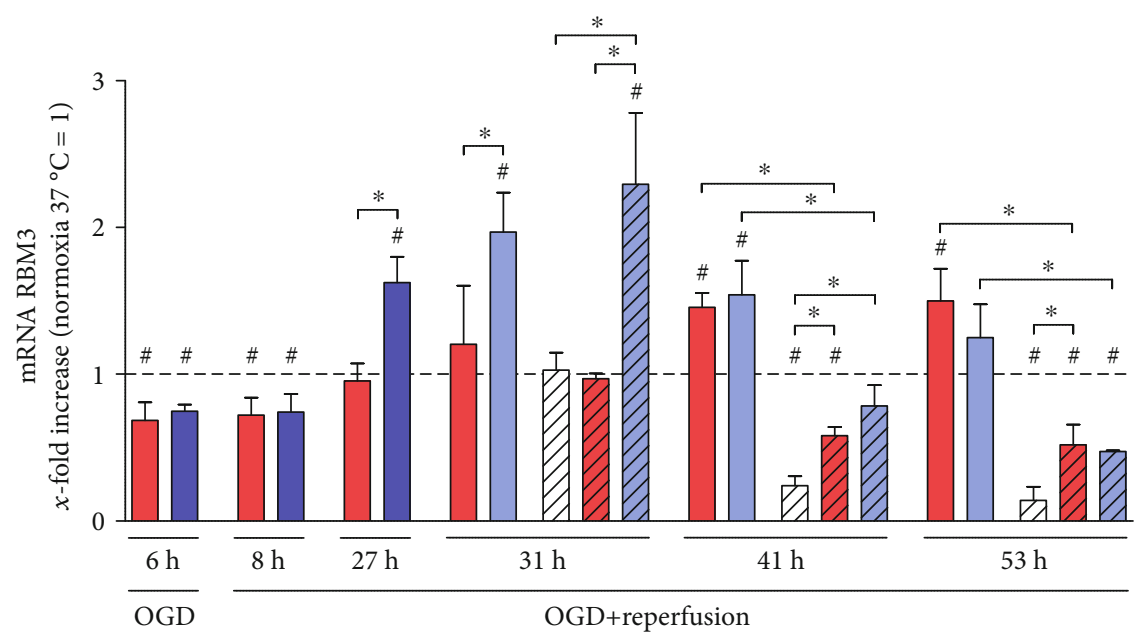

(a)

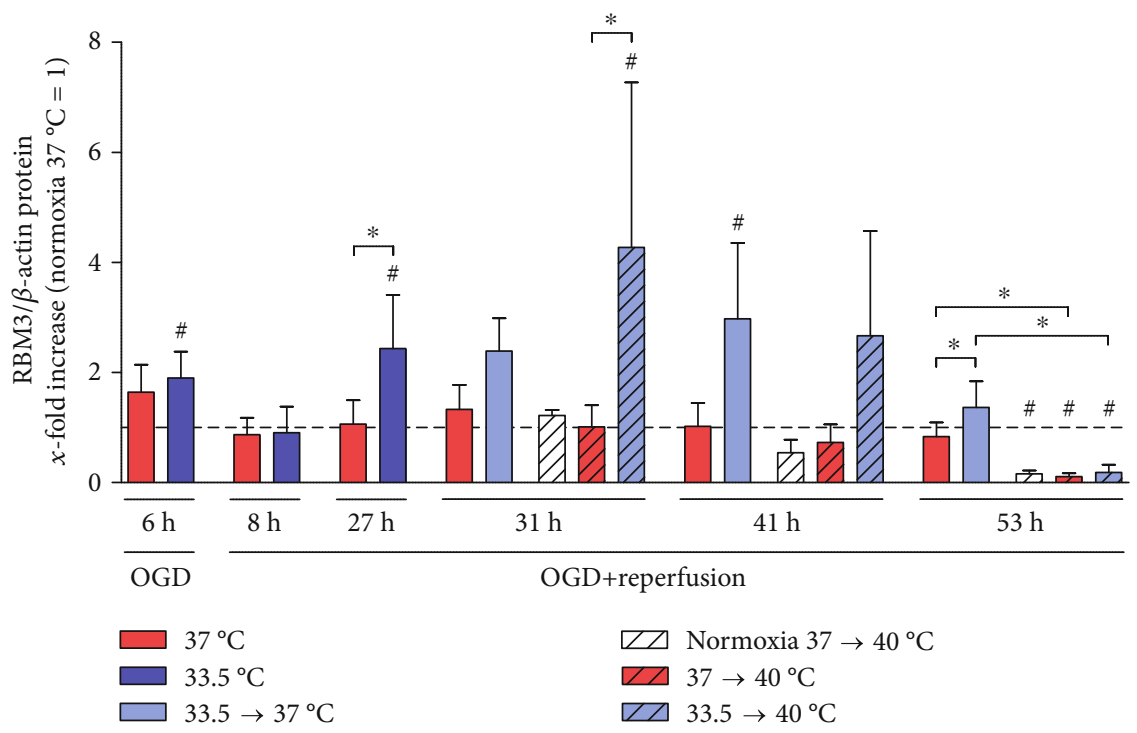

(b)

FIGURE 4: Hypothermia induces while pyrexia inhibits RBM3 (a) mRNA transcriptions and (b) intracellular protein levels in HL-1 cardiomyocytes. Data from 3 to 5 independent experiments is presented as mean \pm SD. ${ }^{*} p \leq 0.05$ and ${ }^{*} p \leq 0.05$ as compared to normoxia control at $37^{\circ} \mathrm{C}$ (normalized to 1 ).

mechanism, in OGD/R-injured cardiomyocytes after warming to pyrexia at $41 \mathrm{~h}$ and $53 \mathrm{~h}$ (see Figure 5). Previous treatment with cooling could temporarily attenuate caspase- 3 cleavage at $41 \mathrm{~h}$ but could not maintain protection for a prolonged exposure to pyrexia $(53 \mathrm{~h})$. Pyrexia in noninjured cardiomyocytes also led to apoptosis ( 31 and $53 \mathrm{~h}$ ), but to a significantly lesser extent than in the OGD/R-injured cells (41 and $53 \mathrm{~h}$ ). Rewarming of the OGD/R-injured cardiomyocytes to normothermia however did not result in increased activation of caspase- 3 .

\section{Discussion}

Ischemia-reperfusion injury causes myocardial cell death by inducing intracellular calcium overload, oxidative stress, and inflammation, which can be exacerbated by pyrexia. IR induces necrotic cell death during the ischemic phase followed by ATP-dependent apoptotic signaling cascades during the reperfusion phase, leading to an apoptosis-induced secondary cell death that can account for up to $50 \%$ of the infarct area [16]. Correspondingly, we previously observed that exposure to OGD induces mitochondrial dysfunction and cell death in the HL-1 cardiomyocytes that could be attenuated by hypothermia $[15,16]$. OGD/R as well as changes in temperature can cause increased production of reactive oxygen species or free radicals, resulting in oxidative stress and terminal apoptosis and/or cell death [19]. In correlation with previous findings, we observed an increase in OGD/R-induced iNOS transcription that was also attenuated by cooling in the HL-1 cardiomyocytes, presumably due to the inhibition of nuclear factor kappa B (NF- $\kappa \mathrm{B})$ translocation to the nucleus [20].

While necrosis is generally observed after an acute ischemic incident, apoptosis is the primary myocardial cell death mechanism following reperfusion. We did not observe 


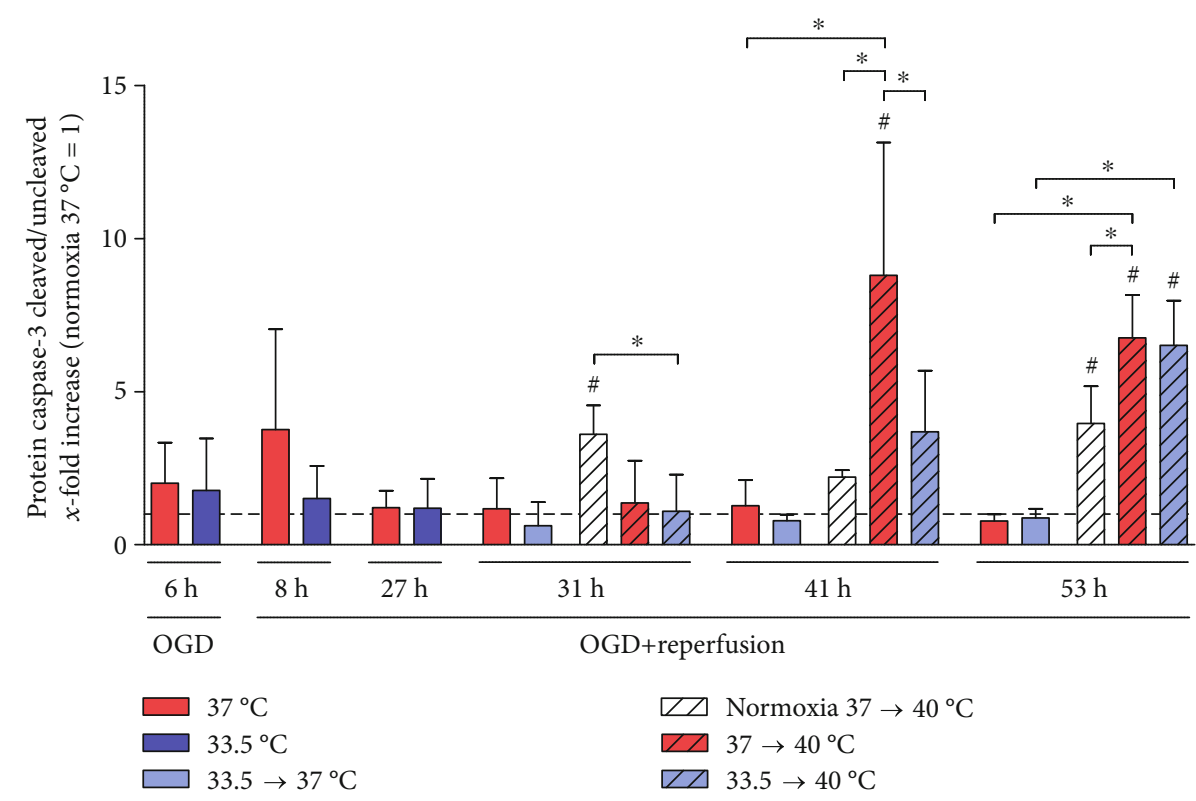

FIgURE 5: Pyrexia induces caspase- 3 cleavage in the OGD/R-injured cardiomyocytes ( 41 and $53 \mathrm{~h}$ ) that was briefly attenuated by hypothermia $(41 \mathrm{~h})$. Undamaged normoxia control cardiomyocytes warmed to pyrexia also showed increased cleavage of caspase-3 ( 31 and $53 \mathrm{~h}$ ). Data from 3 to 4 independent experiments is presented as mean $\pm \mathrm{SD} .{ }^{*} p \leq 0.05$ and ${ }^{\#} p \leq 0.05$ as compared to normoxia control at $37^{\circ} \mathrm{C}$ (normalized to 1).

the induction of apoptosis in the reperfusion phase, but warming to pyrexia after OGD/R with or without hypothermia resulted in the induction of apoptosis, as evidenced by significant increases in the cleavage of caspase- 3 ( $53 \mathrm{~h})$. Unlike necrosis, apoptosis can have beneficial effects and be reversed by the activation of prosurvival pathways, including the Janus kinase- (JAK-) STAT signaling pathway in which cardiacspecific SOCS-3 plays a key role in promoting myocardial IR-induced injury [21]. Nagata et al. observed that induced cardiac-specific SOCS-3 expression correlated with decreased activation of prosurvival STAT3, AKT, and ERK1/2, as well as decreased expression of myeloid cell leukemia-1 (Mcl-1), a member of the antiapoptotic Bcl-2 family. Moreover, they also observed significantly reduced cleavage of caspase- 3 and smaller infarct sizes in cardiac-specific SOCS-3-KO mice at 6 hours and 24 hours after reperfusion, respectively [22]. This is in correlation with our findings that pyrexia induces SOCS-3 expression, resulting in increased cleavage of caspase-3, which could be temporarily attenuated by hypothermia. We previously observed that hypothermia significantly increased the $\mathrm{Bcl}-2 / \mathrm{Bax}$ ratio to protect OGD/R-injured HL-1 cardiomyocytes from apoptosis [16] but did not observe any significant increases upon warming to pyrexia (data not shown). However, the expression of Mcl-1 warrants further investigation as a key STAT3 activator gene of apoptosis after myocardial IR-induced injury.

Moreover, our observation of suppressed RBM3 expression by pyrexia in the HL-1 cardiomyocytes corresponds with previous findings that showed that blood RBM3 mRNA levels were also decreased in febrile children [23]. RBM3 has been shown in vitro to have antiapoptotic effects in a variety of cellular stress situations, including OGD/R, staurosporine, $\mathrm{H}_{2} \mathrm{O}_{2}$, and nitric oxide (NO) treatment, by attenuating caspase- 3 activation and PARP cleavage, as well as inducing Bcl-2 expression [24-26]. Our observation of increased caspase-3 activation in conjunction with suppressed RBM3 expression by pyrexia in OGD/R-injured cardiomyocytes further supports the cytoprotective properties of RBM3 and warrants further investigation as a promising therapeutic strategy against IR injury.

The heart is normally not a key source of inflammatory cytokines and therefore is not considered an immunologically active organ [27]. However, a variety of stresses, including infection by pathogens, mechanical stretch, oxidative stress, and ischemia, can induce innate immune responses that can lead to acute inflammation, and the extent of the inflammatory response after an acute ischemic incident is a key factor that dictates the severity of damage to cardiac tissue. Moreover, IR injury induces the release of host damageassociated molecular patterns (DAMPs) into the extracellular matrix where they bind to various pattern recognition receptors (PRRs) on the surface of neighboring structural cardiac cells, such as cardiomyocytes, endothelial cells, and fibroblasts, or recruited immune cells to also activate endogenous inflammatory signaling cascades (see Figure 6). This activates various signaling transcription factors, in particular NF- $\kappa \mathrm{B}$, to induce the expression of proinflammatory cytokines, including IL-1 $\beta$, IL-18, IL-6, and TNF- $\alpha$ [28].

In correlation with previous reported findings [27], we did not observe significant changes in IL- $1 \beta$ transcription after exposure to OGD/R and hypothermia followed by rewarming to normothermia. However, we did observe significant increases in IL- $1 \beta$ transcription after prolonged exposure to pyrexia ( $53 \mathrm{~h}$ ), which could be attenuated by preceding hypothermia. Interestingly, this pyrexia-induced expression of IL- $1 \beta$ correlates with the significant induction 


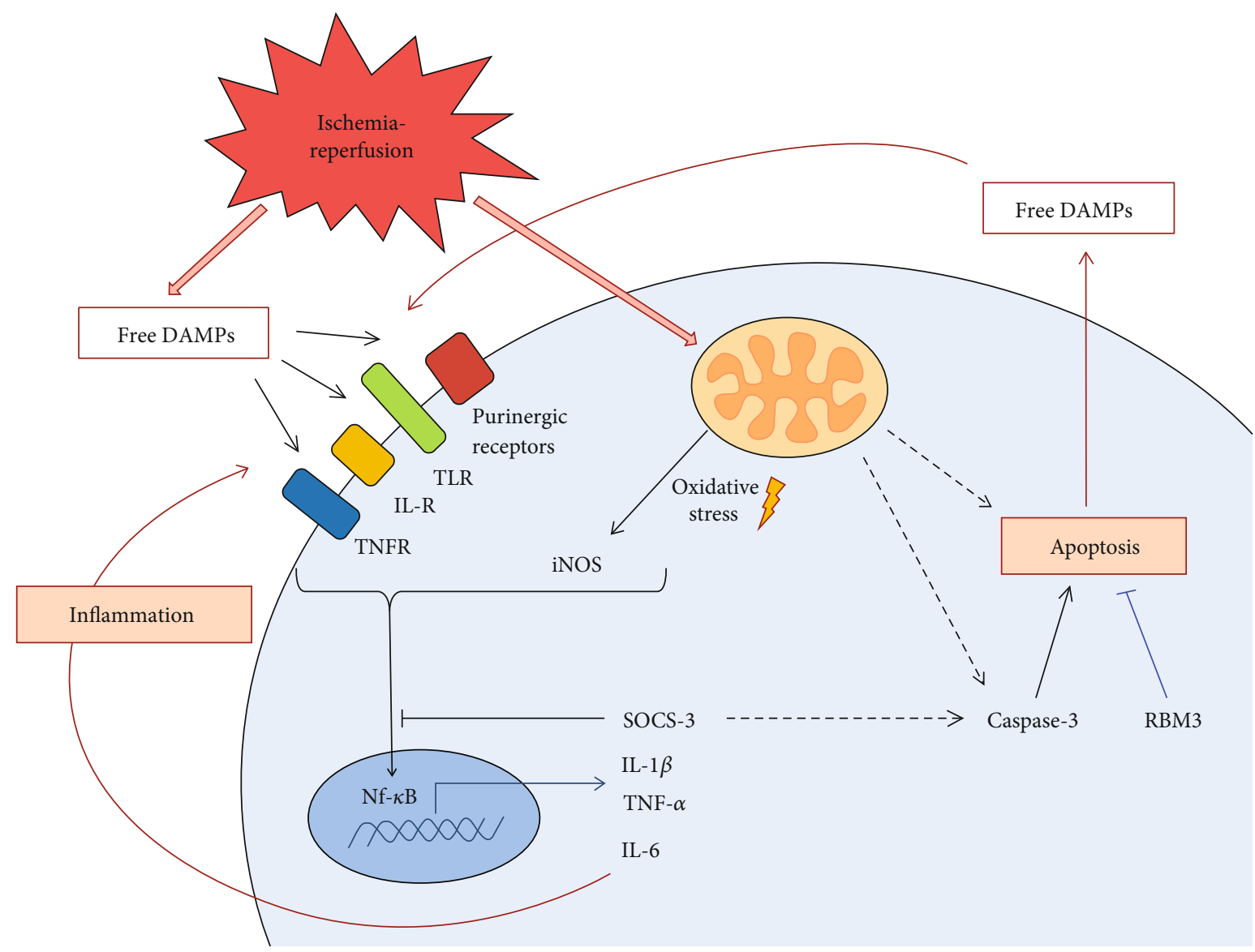

FIGURE 6: Synopsis of the sterile inflammatory response and myocardial apoptotic cell death induced by ischemia-reperfusion injury, hypothermia, and post-TTM rebound pyrexia in the HL-1 cardiomyocytes.

of IL- 6 transcription observed at the same time point after warming to pyrexia. Our findings further support previous reports of increased IL-6 expression in cardiomyocytes in response to increased IL- $1 \beta$ [28], which acts to recruit leukocytes and propagates inflammation in the heart [29]. We also observed a tendency towards increased MCP-1/CCL2 transcription after warming to pyrexia, though not to significance, that also plays a role in regulating leukocyte trafficking (data not shown).

IL-6 has been shown to have cardioprotective effects [29], but chronic or excessive expression of IL-6 can be fatal and has been shown to cause heart failure in a rodent model [30]. Additionally, IL- 6 along with IL- $1 \beta$ and TNF- $\alpha$ has been known to act as endogenous pyrogens, thus contributing to the induction of fever [31]. We observed that cooling effectively maintained IL-6 transcription at normoxia control levels at all investigated time points and throughout rewarming to $37^{\circ} \mathrm{C}$. Therefore, attenuating IL- 6 expression in cardiomyocytes may be an essential strategy to minimize the systemic inflammatory response often referred to as rebound pyrexia in hypothermia-treated cardiac arrest patients.

SOCS-3 is a member of the STAT-induced STAT inhibitor (SSI) family that functions as a negative regulator of cytokine signaling to control immune homeostasis in both physiological and pathological conditions. It therefore plays an important role in restraining inflammation, yet allowing optimal immune response against infections. However, similar to the findings of Nagata et al., we also observed significant increases in TNF- $\alpha$, IL- 6 , and IL- $1 \beta$ transcriptions relative to normoxia control that correlated with significant increases in SOCS-3 in the OGD/R groups upon warming to pyrexia [20], whereas previously cooled OGD/R groups rewarmed to normothermia did not show this inflammatory response and even resulted in attenuated IL-1 $\beta$ expression.

Limitations of our study lie in the use of a cardiomyocyte monoculture model, as our focus was to investigate the specific contribution of resident cardiomyocytes to the inflammatory response. Of course the interaction between leukocytes, cardiac fibroblasts, and resident cardiomyocytes plays an important role in the inflammatory response after IR-induced cardiac injury and warrants further investigation. Moreover, the release of cardiac-specific DAMPs from necrotic myocardial cells was not addressed in this study but is currently under investigation in a primary murine cardiomyocyte model in our lab.

\section{Conclusion}

Targeted temperature management is an effective therapeutic strategy for ischemia/reperfusion injury, but preventing post- 
TTM rebound pyrexia is crucial to minimizing the sterile inflammatory response and subsequent cardiomyocyte apoptosis after an acute ischemia-reperfusion injury. Optimization of the TTM protocol for postcardiac arrest care is currently a topic of great research interest. Although most efforts are focused on the application of TTM, including optimal cooling temperature, rates of cooling and subsequent rewarming, practical methods of cooling that allow for adequate and consistent temperature control, and eligible patient cohort, preventing the onset of post-TTM rebound pyrexia warrants further investigation. Our findings show that maintaining a period of post-TTM normothermia, referred to as "therapeutic normothermia" by Leary et al., is effective in preventing secondary apoptosisdriven myocardial cell death, thus minimizing the infarct area and further release of various mediators of the innate sterile inflammatory response after an acute ischemia/reperfusion injury.

\section{Abbreviations}

\begin{tabular}{|c|c|}
\hline AMI: & Acute myocardial infarction \\
\hline AKT: & Protein kinase B \\
\hline ATP: & Adenosine triphosphate \\
\hline Bax: & Bcl-2-associated X protein \\
\hline Bcl-2: & B-cell lymphoma 2 \\
\hline BSA: & Bovine serum albumin \\
\hline DAMPs: & Damage-associated molecular patterns \\
\hline EDTA: & Ethylenediaminetetraacetic acid \\
\hline ERK1/2: & $\begin{array}{l}\text { Extracellular signal-regulated protein } \\
\text { kinases } 1 \text { and } 2\end{array}$ \\
\hline FBA: & Fetal bovine serum \\
\hline GAPDH: & Glyceraldehyde-3-phosphate dehydrogenase \\
\hline HIE: & Hypoxic/ischemic encephalopathy \\
\hline IL-1 $\beta /-6 /-18:$ & Interleukin-1 $\beta /-6 /-18$ \\
\hline iNOS: & Inducible nitric oxide synthase \\
\hline IOTH: & Intra-OGD therapeutic hypothermia \\
\hline IR: & Ischemia-reperfusion \\
\hline JAK-STAT: & $\begin{array}{l}\text { Janus kinase/signal transducers and activa- } \\
\text { tors of transcription }\end{array}$ \\
\hline Mcl-1: & Myeloid cell leukemia-1 \\
\hline MCP-1/CCL2: & $\begin{array}{l}\text { Monocyte chemoattractant protein-1/CC- } \\
\text { chemokine ligand } 2\end{array}$ \\
\hline (m)RNA: & (Messenger) ribonucleic acid \\
\hline $\mathrm{NF}-\kappa \mathrm{B}:$ & Nuclear factor kappa B \\
\hline NO: & Nitric oxide \\
\hline OGD/R: & Oxygen-glucose deprivation/reperfusion \\
\hline PARP: & Poly(ADP-ribose) polymerase 1 \\
\hline PRRs: & Pattern recognition receptors \\
\hline PVDF: & Polyvinylidene difluoride \\
\hline RBM3: & RNA binding motif 3 \\
\hline RIPA buffer: & Radioimmunoprecipitation assay buffer \\
\hline SDS: & Sodium dodecyl sulfate \\
\hline SOCS-3: & Suppressor of cytokine signaling 3 \\
\hline STAT3: & $\begin{array}{l}\text { Signal transducer and activator of transcrip- } \\
\text { tion } 3\end{array}$ \\
\hline TH: & Therapeutic hypothermia \\
\hline TNF- $\alpha$ : & Tumor necrosis factor-alpha \\
\hline TTM: & Targeted temperature management. \\
\hline
\end{tabular}

\section{Data Availability}

The (experimental) data used to support the findings of this study are available from the corresponding author upon request.

\section{Conflicts of Interest}

The authors declare that they have no competing interests.

\section{Authors' Contributions}

Giang Tong and Nalina N. A. von Garlen contributed equally to the drafting of the manuscript.

\section{Acknowledgments}

We thank Nora Kuenzel for her expertise and technical assistance in experimental procedures. This study was supported by a research grant from the German Heart Research Foundation (Deutsche Stiftung für Herzforschung) (Project No. F/53/17). We acknowledge the support from the German Research Foundation (DFG) and the Open Access Publication Fund of Charité - Universitätsmedizin Berlin.

\section{References}

[1] K. Martinello, A. R. Hart, S. Yap, S. Mitra, and N. J. Robertson, "Management and investigation of neonatal encephalopathy: 2017 update," Archives of Disease in Childhood - Fetal and Neonatal Edition, vol. 102, no. 4, pp. F346-F358, 2017.

[2] C. W. Callaway, M. W. Donnino, E. L. Fink et al., "Part 8: postcardiac arrest care: 2015 American Heart Association guidelines update for cardiopulmonary resuscitation and emergency cardiovascular care," Circulation, vol. 132, 18_Supplement_2, pp. S465-S482, 2015.

[3] H. Kirkegaard, E. Soreide, I. de Haas et al., "Targeted temperature management for 48 vs 24 hours and neurologic outcome after out-of-hospital cardiac arrest: a randomized clinical trial," JAMA, vol. 318, no. 4, pp. 341-350, 2017.

[4] M. Leary, A. V. Grossestreuer, S. Iannacone et al., "Pyrexia and neurologic outcomes after therapeutic hypothermia for cardiac arrest," Resuscitation, vol. 84, no. 8, pp. 1056-1061, 2013.

[5] N. Nielsen, J. Wetterslev, T. Cronberg et al., "Targeted temperature management at $33^{\circ} \mathrm{C}$ versus $36^{\circ} \mathrm{C}$ after cardiac arrest," The New England Journal of Medicine, vol. 369, no. 23, pp. 2197-2206, 2013.

[6] A. Abu-Arafeh, A. Rodriguez, R. L. Paterson, and P. J. D. Andrews, "Temperature variability in a modern targeted temperature management trial," Critical Care Medicine, vol. 46, no. 2, pp. 223-228, 2018.

[7] A. Rungatscher, G. B. Luciani, D. Linardi et al., "Temperature variation after rewarming from deep hypothermic circulatory arrest is associated with survival and neurologic outcome," Therapeutic Hypothermia and Temperature Management, vol. 7, no. 2, pp. 101-106, 2017.

[8] R. C. Baena, R. Busto, W. D. Dietrich, M. Y. T. Globus, and M. D. Ginsberg, "Hyperthermia delayed by 24 hours aggravates neuronal damage in rat hippocampus following global ischemia," Neurology, vol. 48, no. 3, pp. 768-773, 1997. 
[9] A. Diwan, T. Tran, A. Misra, and D. Mann, "Inflammatory mediators and the failing heart: a translational approach," Current Molecular Medicine, vol. 3, no. 2, pp. 161-182, 2003.

[10] E. Mezzaroma, S. Toldo, D. Farkas et al., "The inflammasome promotes adverse cardiac remodeling following acute myocardial infarction in the mouse," Proceedings of the National Academy of Sciences of the United States of America, vol. 108, no. 49, pp. 19725-19730, 2011.

[11] G. Torre-Amione, S. Kapadia, C. Benedict, H. Oral, J. B. Young, and D. L. Mann, "Proinflammatory cytokine levels in patients with depressed left ventricular ejection fraction: a report from the Studies of Left Ventricular Dysfunction (SOLVD)," Journal of the American College of Cardiology, vol. 27, no. 5, pp. 1201-1206, 1996.

[12] D. Kalra, B. Bozkurt, A. Deswal, G. Torre-Amione, D. L. Mann, and D. L. Mann, "Experimental options in the treatment of heart failure: the role of cytokine antagonism," Heart failure monitor, vol. 1, no. 4, pp. 114-121, 2001.

[13] K. E. Porter and N. A. Turner, "Cardiac fibroblasts: at the heart of myocardial remodeling," Pharmacology \& Therapeutics, vol. 123, no. 2, pp. 255-278, 2009.

[14] T. Aoyagi and T. Matsui, "The cardiomyocyte as a source of cytokines in cardiac injury," Journal of Cell Science \& Therapy, vol. s5, 2012.

[15] G. Tong, C. Walker, C. Bührer, F. Berger, O. Miera, and K. R. L. Schmitt, "Moderate hypothermia initiated during oxygenglucose deprivation preserves HL-1 cardiomyocytes," Cryobiology, vol. 70, no. 2, pp. 101-108, 2015.

[16] J. Krech, G. Tong, S. Wowro et al., "Moderate therapeutic hypothermia induces multimodal protective effects in oxygenglucose deprivation/reperfusion injured cardiomyocytes," Mitochondrion, vol. 35, pp. 1-10, 2017.

[17] W. C. Claycomb, N. A. Lanson Jr., B. S. Stallworth et al., "HL-1 cells: a cardiac muscle cell line that contracts and retains phenotypic characteristics of the adult cardiomyocyte," Proceedings of the National Academy of Sciences of the United States of America, vol. 95, no. 6, pp. 2979-2984, 1998.

[18] J. P. Nolan and A. Cariou, "Post-resuscitation care: ERCESICM guidelines 2015," Intensive Care Medicine, vol. 41, no. 12, pp. 2204-2206, 2015.

[19] J. K. Brunelle and N. S. Chandel, "Oxygen deprivation induced cell death: an update," Apoptosis, vol. 7, no. 6, pp. 475-482, 2002.

[20] H. S. Han, Y. Qiao, M. Karabiyikoglu, R. G. Giffard, and M. A. Yenari, "Influence of mild hypothermia on inducible nitric oxide synthase expression and reactive nitrogen production in experimental stroke and inflammation," Journal of Neuroscience, vol. 22, no. 10, pp. 3921-3928, 2002.

[21] B. Carow and M. E. Rottenberg, "SOCS3, a major regulator of infection and inflammation," Frontiers in Immunology, vol. 5, p. 58, 2014.

[22] T. Nagata, H. Yasukawa, S. Kyogoku et al., "Cardiac-specific SOCS3 deletion prevents in vivo myocardial ischemia reperfusion injury through sustained activation of cardioprotective signaling molecules," PLoS One, vol. 10, no. 5, article e0127942, 2015.

[23] J. J. L. Wong, A. Y. M. Au, D. Gao et al., "RBM3 regulates temperature sensitive miR-142-5p and miR-143 (thermomiRs), which target immune genes and control fever," Nucleic Acids Research, vol. 44, no. 6, pp. 2888-2897, 2016.
[24] A. L. Ferry, P. W. Vanderklish, and E. E. Dupont-Versteegden, "Enhanced survival of skeletal muscle myoblasts in response to overexpression of cold shock protein RBM3," American Journal of Physiology-Cell Physiology, vol. 301, no. 2, pp. C392C402, 2011.

[25] S. Chip, A. Zelmer, O. O. Ogunshola et al., "The RNA-binding protein RBM3 is involved in hypothermia induced neuroprotection," Neurobiology of Disease, vol. 43, no. 2, pp. 388-396, 2011.

[26] H. J. Yang, F. Ju, X. X. Guo et al., "RNA-binding protein RBM3 prevents NO-induced apoptosis in human neuroblastoma cells by modulating p38 signaling and miR-143," Scientific Reports, vol. 7, no. 1, article 41738, 2017.

[27] S. Kapadia, Z. Dibbs, K. Kurrelmeyer et al., "The role of cytokines in the failing human heart," Cardiology Clinics, vol. 16, no. 4 , pp. 645-656, 1998, viii.

[28] F. Braza, S. Brouard, S. Chadban, and D. R. Goldstein, "Role of TLRs and DAMPs in allograft inflammation and transplant outcomes," Nature Reviews Nephrology, vol. 12, no. 5, pp. 281-290, 2016.

[29] J. A. Fontes, N. R. Rose, and D. Čiháková, “The varying faces of IL-6: From cardiac protection to cardiac failure," Cytokine, vol. 74, no. 1, pp. 62-68, 2015.

[30] T. Tanaka and T. Kishimoto, "Targeting interleukin-6: all the way to treat autoimmune and inflammatory diseases," International Journal of Biological Sciences, vol. 8, no. 9, pp. 12271236, 2012.

[31] P. A. Mackowiak, "Concepts of fever," Archives of Internal Medicine, vol. 158, no. 17, pp. 1870-1881, 1998. 


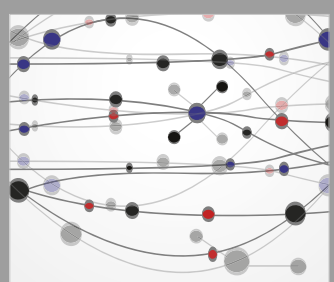

The Scientific World Journal
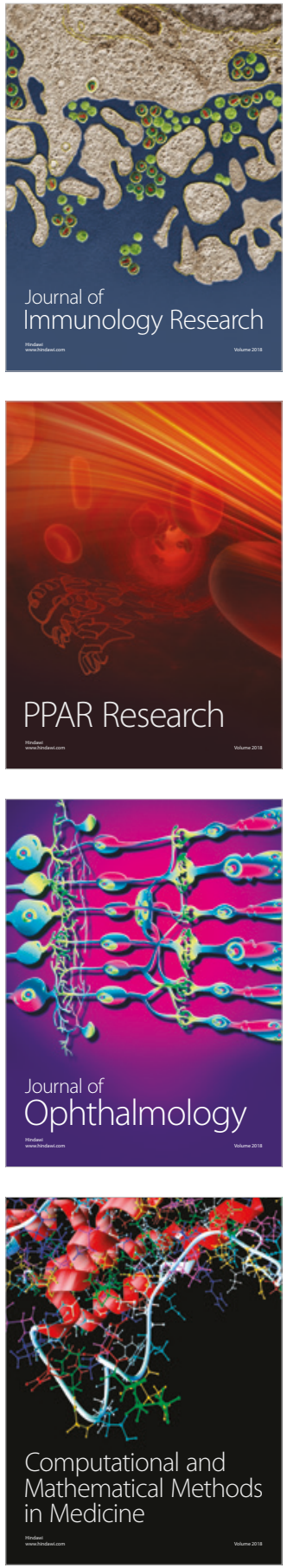

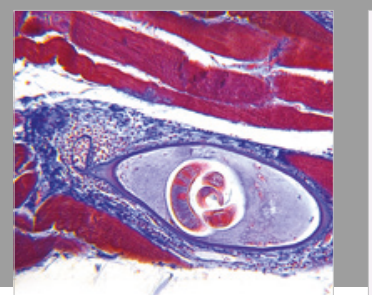

Gastroenterology Research and Practice

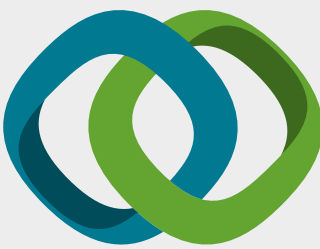

\section{Hindawi}

Submit your manuscripts at

www.hindawi.com
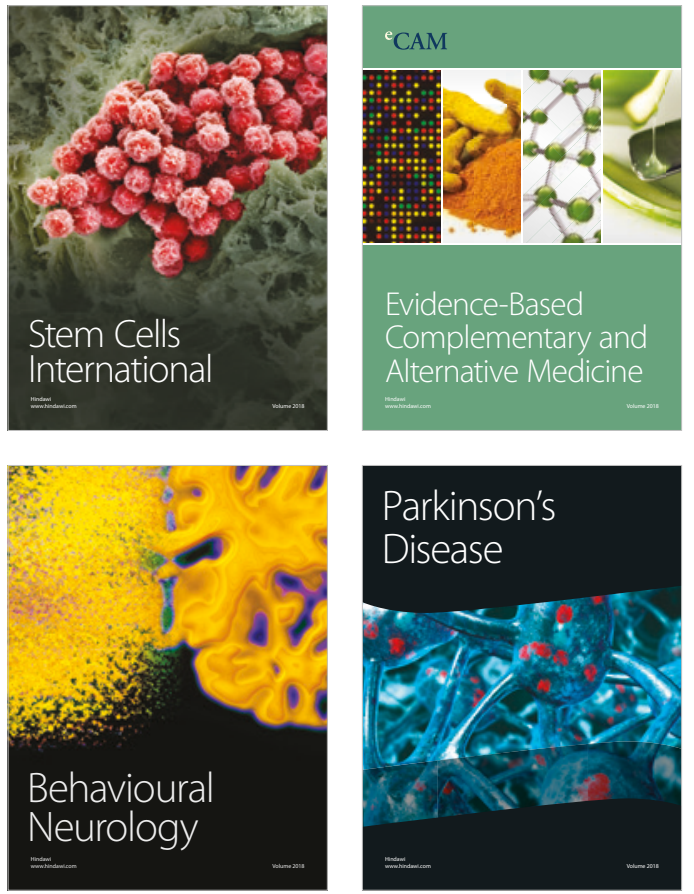

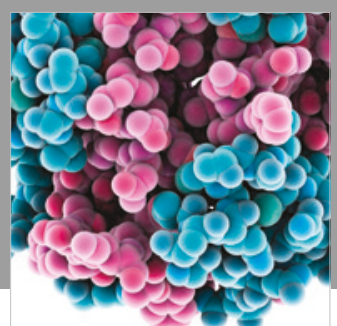

ournal of

Diabetes Research

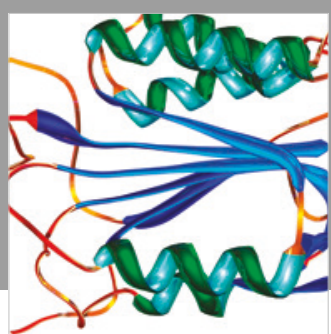

Disease Markers
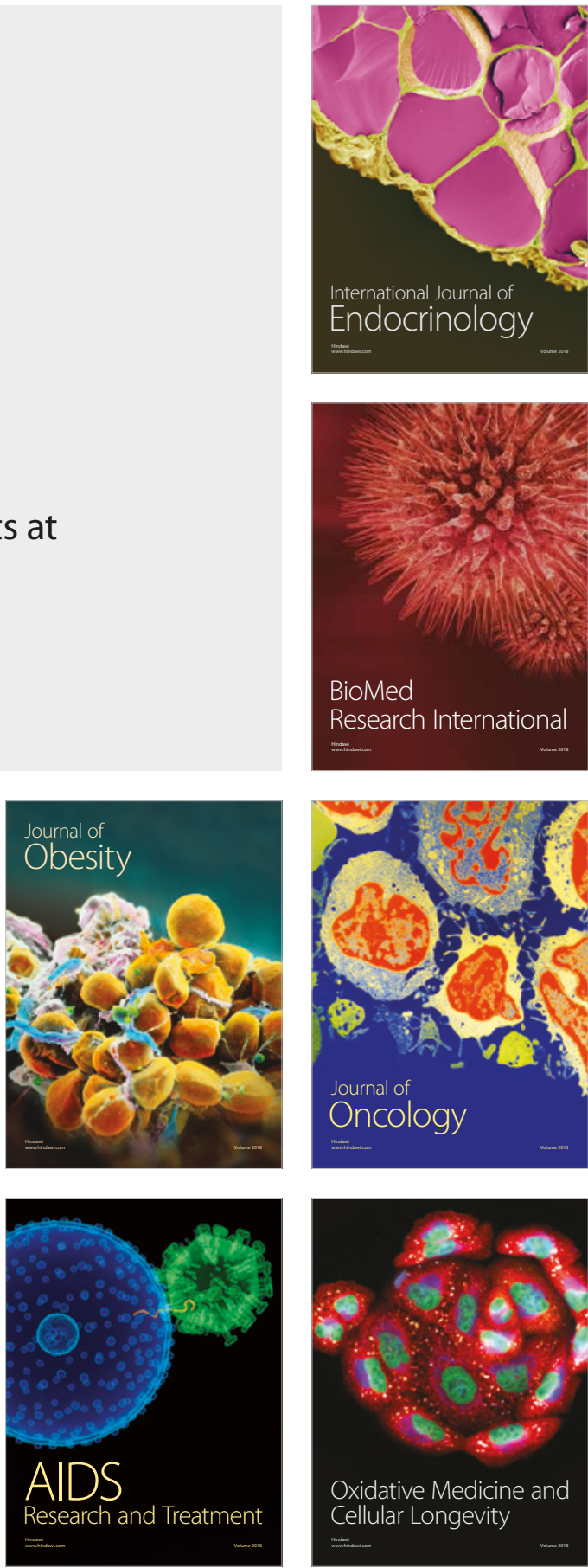